\title{
The Evaluation of Clinicopathological and Immunohistochemical Findings of Cervical Clear Cell Carcinoma in a Bitch
}

\author{
Kubra Karakas Alkan', Mehmet Eray Alcigir² \& Hasan Alkan³
}

\begin{abstract}
Background: Clear cell carcinoma (CCC) of the cervix is a rarely seen malignant tumor which is classified in adenocarcinomas of the endometrium. It is responsible for $2.15-3.0 \%$ of endometrial tumors. The diagnosis is difficult and is still controversial in uterine carcinomas. Macroscopically, masses were protruding to endometrial surface. However, the definitive diagnosis was carried by microscopical evaluation. The cells contain clear cytoplasm. The cells are seen in this pattern because there is either glycogenation or secretoric activity in the cells.

Case: In the present case, clinicopathologic and immunohistochemical findings of clear cell carcinoma of the cervix were defined in a 3 year-old spayed Golden retriever bitch. Previously spayed bitch, which had vaginal discharge for the last month-long, was submitted to the Department of Obstetrics and Gynecology, Ankara University, Faculty of Veterinary Medicine. In the general clinical examination, vaginoscopy was performed and vaginal cytology was obtained from smear. The source of discharge was detected as cervix uteri. In vaginal cytologic examination, erythrocyte, neutrophile and superficial cells were observed. In abdominal ultrasonography, a hypoechoic mass was detected at cranial part of the urinary bladder. To evaluate the general health condition of the dog, total blood counting and serum biochemistry were analyzed in addition to assessing its hormone prophlye. Estrogen and progesterone levels were evaluated. Estradiol (E2) level was measured as $23 \mathrm{pg} / \mathrm{mL}$ and progesterone level was measured as $1.96 \mathrm{ng} / \mathrm{mL}$ from collected serum. The cervical mass in diameters of $3 \times 4 \times 2.5 \mathrm{~cm}$ was removed in operation. In macroscopical examination, it had spherical and regularly shape. After the macroscopical examination, tissue samples were fixed in $10 \%$ buffered formalin. Then, the samples stained with Haematoxylin-Eosin (H\&E), Masson's trichrome and PAS stainings, respectively. At the macroscopic and histological examinations, the mass was diagnosed as clear cell carcinoma. Immunohistochemically, the tumor was stained with CK19 -SMA, vimentin, desmin, TGF-, VEGF, CEA, ER and PR markers. Other markers gave moderate to severe reactions in exception for no or weak ER and PR positivities. In direction of these results, clear cell carcinoma of cervix had been found remarkably due to first description in a spayed bitch on the basis of knowledge.

Discussion: Clear cell carcinoma (CCC) is one type of the endometrial carcinomas. It is frequently known to have aggressive behavior and unfavorable prognosis. In human counterparts, clear cell carcinoma is frequently reoccurred in caudoabdominal and pelvic region even after being removed. The occurrence of clear cell carcinoma has highly increased with diethylstilbestrol usage during pregnancy. The situation on uterine carcinoma is nearly same in domestic animals. It is related to prolonged estrogenism. In this case, the bitch has been under prolong exposure to estrogenic effect. Indeed the estradiol level was high when compared to spayed female. Also, it is thought that the reason of high estradiol level does not depend on the ovarian remnant. It is believed this situation may be relevant to exogen hormone usage. Vaginal smear confirmed erythrocyte (due to bleeding), predominantly superficial cells to it's under estrogenic effect even despite being spayed.
\end{abstract}

Keywords: clear cell carcinoma, cervix, clinicopathology, marker, bitch. 
K.K. Alkan, M.E. Alcigir \& H. Alkan. 2018. The Evaluation of Clinicopathological and Immunohistochemical Findings of

\section{INTRODUCTION}

Clear cell carcinoma (CCC) of the cervix is a rarely seen malignant tumor which is classified in adenocarcinomas of the endometrium [4]. It is responsible for 2.15-3.0\% of endometrial tumors and 10-20\% of all cervical cancer in women [2,3]. It is also known as subtype of Emoid CA. The diagnosis is difficult and is still controversial in uterine carcinomas [13]. CCC in women (between 62 to 67 ) is usually detected in postmenopausal period [2,9]. Macroscopically, masses were protruding to endometrial surface [7]. However, the definitive diagnosis was carried out by microscopical evaluation [12]. The cells contained clear cytoplasm. The cells are seen in this pattern because there is either glycogenation or secretoric activity in the cells [13]. Immunophenotypic profile of CCC was documented that it is not still set clearly in spite of that some studies are performed on this subject $[1,8]$. In the literature review, it was seen that such a problem was not previously seen among dogs.

\section{CASE}

A 3-year-old spayed female dog was submitted to Department of Obstetrics and Gynecology with vaginal discharge. In the information received from its owner it was learned that the dog was spayed approximately one year before and vaginal discharge was seen for nearly one month. Firstly, vaginoscopy was carried out. The source of discharge was detected as cervix uteri. Then, vaginal cytology was performed. In vaginal cytologic examination, erythrocyte, neutrophil and superficial cells were observed. In abdominal ultrasonography (Figure 1), a hypoechoic mass located in a cranial part of the urinary bladder was detected. Additionally, total blood cell count (Table 1) and serum biochemical analysis (Table 2) were performed towards evaluating general health condition of the bitch. Also, blood serum was taken with the aim of detecting its hormone prophyle. Estrogen and progesterone levels were evaluated in a special laboratory. Estradiol level was measured as $23 \mathrm{pg} / \mathrm{mL}$ and progesterone level was measured as $1.96 \mathrm{ng} / \mathrm{mL}$ from collected serum.

Following the examinations, the decision to carry out an operation towards removing the mass was taken. The bitch was starved preoperatively for $12 \mathrm{~h}$. Then, surgery was carried out under general anesthesia. The catheter was placed into vena cephalica and anesthesia induction was performed intravenously using
Table 1. Result of total blood cell count.

\begin{tabular}{|c|c|c|}
\hline \multicolumn{3}{|c|}{ Hematology } \\
\hline Parameter & Results & Reference Values \\
\hline $\mathrm{WBC}\left(\mathrm{m} / \mathrm{mm}^{3}\right)$ & 16.97 & $6-17$ \\
\hline $\operatorname{Lym}(\%)$ & 11.6 & $10-30$ \\
\hline Mon (\%) & 2.3 & $2-10$ \\
\hline $\operatorname{Gra}(\%)$ & 86.1 & $50-80$ \\
\hline $\operatorname{Lym}\left(\mathrm{m} / \mathrm{mm}^{3}\right)$ & 1.96 & $0.6-5.1$ \\
\hline $\operatorname{Mon}\left(\mathrm{m} / \mathrm{mm}^{3}\right)$ & 0.39 & $0.1-1.7$ \\
\hline $\operatorname{Gra}\left(\mathrm{m} / \mathrm{mm}^{3}\right)$ & 14.62 & $3-13.6$ \\
\hline $\mathrm{RBC}\left(\mathrm{M} / \mathrm{mm}^{3}\right)$ & 6.0 & $5.5-8.5$ \\
\hline MCV (fL) & 59.6 & $58-73$ \\
\hline $\operatorname{Hct}(\%)$ & 35.7 & $35-55$ \\
\hline $\mathrm{MCH}(\mathrm{pg})$ & 19.0 & $19.5-24.5$ \\
\hline $\mathrm{MCHC}(\mathrm{g} / \mathrm{dL})$ & 31.9 & $28-40$ \\
\hline RDW & 12.7 & $8-12$ \\
\hline $\mathrm{Hb}(\mathrm{g} / \mathrm{dL})$ & 11.4 & $10-18$ \\
\hline $\operatorname{PLT}\left(\mathrm{m} / \mathrm{mm}^{3}\right)$ & 143 & $120-600$ \\
\hline MPV (fL) & 7.6 & $5-12$ \\
\hline $\operatorname{Pct}(\%)$ & 0.11 & --- \\
\hline
\end{tabular}

Table 2. Serum biochemical analysis.

\begin{tabular}{ccc}
\hline \multicolumn{3}{c}{ Serum Biochemical Parameters } \\
\hline Analyse & Results & Reference Values \\
\hline BUN (mg/dL) & 16 & $5.6-11.8$ \\
Creatinine (mg/dL) & 1.1 & $0.5-1.5$ \\
SGOT (UI/L) & 41 & $10-88$ \\
SGPT (UI/L) & 44 & $10-88$ \\
ALP (UI/L) & 188 & $20-150$ \\
LDH (UI/L) & 131 & $50-495$ \\
T. Bilirubin (mg/dL) & 0.4 & $0.1-0.6$ \\
Phosphor (mg/dL) & 3.9 & $2.2-5.5$ \\
Albumin (g/dL) & 3.1 & $2.3-3.8$ \\
Cholesterol (mg/dL) & 130 & $125-270$ \\
Triglyceride (mg/dL) & 31 & $20-112$ \\
\hline
\end{tabular}

Propofol (Propofol $\left.{ }^{\circledR} \% 1\right)^{1}$ at $6 \mathrm{mg} / \mathrm{kg}$. The bitch under anesthesia was placed on a table turning toward into its dorsal flank. It was intubated via the orotracheal route. General anesthesia was continued using isoflurane (Forane ${ }^{\circledR}$ Likid) ${ }^{2}$ during operation. The operation was carried out with adopting the ventromedial approach- 
ment of the abdominal cavity. The mass was removed from fore part of cervix by tying ligature. During the operation, any ovarian remnant was not encountered.

During the macroscopical examination, the mass in diameter was $3 \times 4 \times 2.5 \mathrm{~cm}$. It had spherical and a regular shape. After the macroscopical examination, tissue samples were fixed in $10 \%$ buffered formalin. Then, the samples were processed routinely, embedded in paraffin wax and stained with HaematoxylinEosin (H\&E), Masson's trichrome and PAS stainings, respectively. There were some protrusions to the surface of the endometrium. Myometrium was thickened (Figure 2A). Histopathologically, sheets of atypical gland epitheliums with clear cytoplasms and hobnail cells comprised solid patterns (Figure 2B). The cells included clear cytoplasm within the presence of glycogen and atypic nuclei with eccentric location. In Masson's trichrome staining, the infiltrative cells were observed between muscle bundles. Muscle cells were differentiated from this fibrous stroma including fibrocytes and fibroblasts (Figure 2C). In PAS staining, their cytoplasms contained eosinophilic mucinous content (Figure 2D).

After the diagnosis of the tumor, the tissue sections were stained immunohistologically by using Strept ABC-P kit (Novocastra ${ }^{\mathrm{TM}}$ Peroxidase Detection Systems RE7110-K/RE7120-K) ${ }^{3}$ and markers (CK19, $\alpha$ SMA, vimentin, desmin, CEA, TGF- $\beta$, VGEF, ER, PR) [Table 3)]. For this aim, trypsinization with $1 \%$ trypsin, antigen demasking with Citrate Buffer (pH6.0) for CEA, TGF- $\beta$, ER and PR and protein blocking were performed. After each step, the sections were treated with PBS. Counterstaining was done with Gill's hematoxylin. DAB chromogen was used as a color indicator. For control sections, PBS was used instead of the markers. The reactions were semiquantitatively scored as - (negative) $,+(<30 \%),++(30-70 \%)$ and $+++(>70 \%)$ at $x 400 \mathrm{HPF}$ counting 10 fields. Immunohistochemically, the positivities and its localizations are shown in Table 4. All positivities were seen in cytoplasms of the cells (Figures 2E-I).

\section{DISCUSSION}

Clear cell carcinoma (CCC) is one type of the endometrial carcinomas. It is frequently known to have aggressive behavior and unfavorable prognosis. In human counterparts, $\mathrm{CCC}$ is frequently reoccurred in caudoabdominal and pelvic region even after being

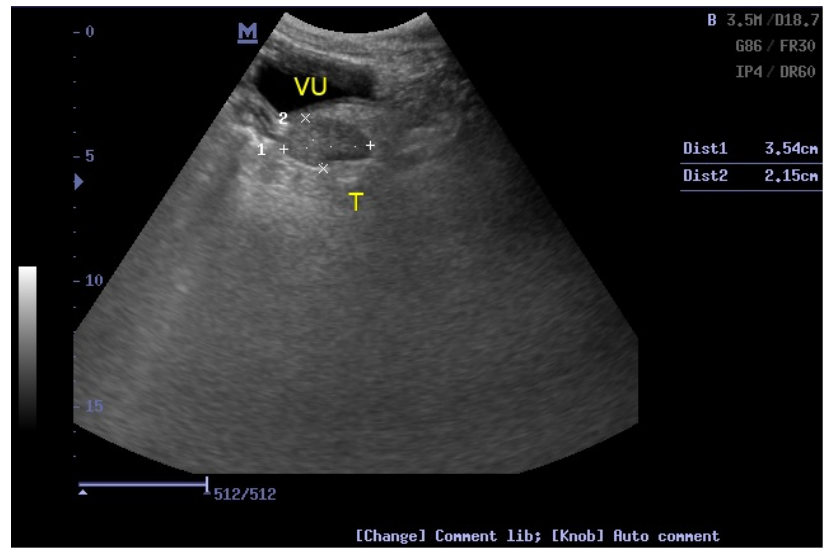

Figure 1. Ultrasonographic image of the mass.

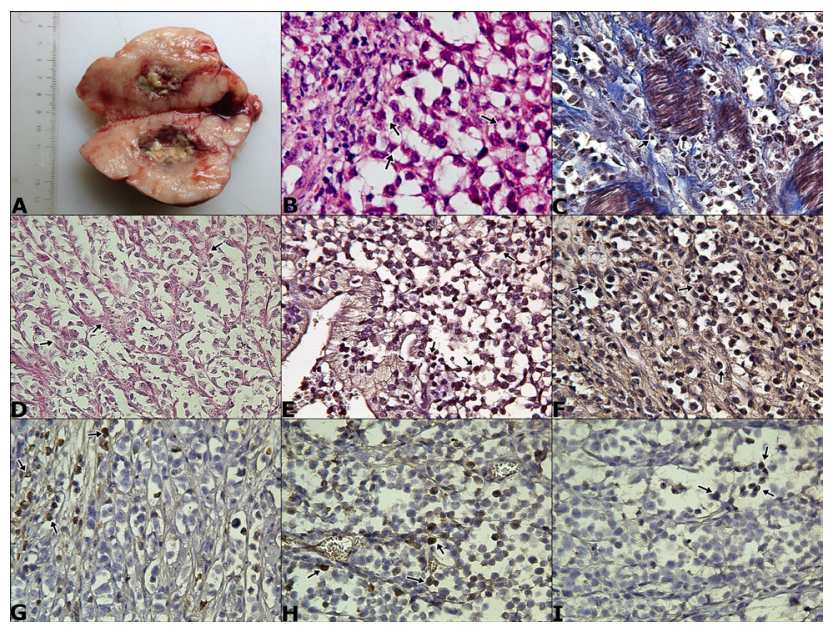

Figure 2. A- Cut view of corpus uteri. B-Anaplastic clear cells infiltrating myometrium (arrows) [x400, HE]. C-Anaplastic clear cells between muscle and collagen bundles [x400, Masson's trichrome staining]. D- PAS positive clear cells (arrows) [x400, PAS staining]. E- CK19 positive clear cells (arrows) $[\mathrm{x} 400, \mathrm{ABC}-\mathrm{P}]$. F- Desmin positive cells (arrows) [x400, ABC-P]. $\mathrm{G}-\mathrm{TGF}-\beta$ positive clear cells (arrows) $[\mathrm{x} 400, \mathrm{ABC}-\mathrm{P}]$. H- Estrogen receptor positive clear cells [x400, ABC-P]. I- Progesterone receptor positive clear cells, $\mathrm{x} 400$, ABC-P.

removed [5]. The occurrence of clear cell carcinoma has highly increased with diethylstilbestrol (DES) usage during pregnancy and seen in middle aged women. The situation on uterine carcinoma is nearly same in domestic animals. It is related to prolonged estrogenism [10]. The tumor grows infiltratively towards the stroma of cervix and corpus uteri [6]. In this case, the bitch has been under prolong exposure to estrogenic effect. Indeed estradiol level was high when compared to spayed female. Also, it is thought that the reason of high estradiol level does not depend on the ovarian remnant. It is believed this situation may be relevant to exogen hormone usage. Vaginal smear confirmed erythrocyte (due to bleeding), predominantly superficial cells to it's under estrogenic effect even despite being spayed. Although the morphology of CCC cells is known, it has been stated 
K.K. Alkan, M.E. Alcigir \& H. Alkan. 2018. The Evaluation of Clinicopathological and Immunohistochemical Findings of

Table 3. Marker panel.

\begin{tabular}{cccc}
\hline Marker & Features & Source & Dilution \\
\hline Cytokeratin (CK)19 & Monoclonal mouse & DAKO & $1: 50$ \\
Transforming Growth Factor (TGF)- $\beta 1$ & Polyclonal rabbit & Santacruz Biotechnology, Inc & $1: 100$ \\
Carcinoembryonic Antigen (CEA) & Monoclonal mouse & Neomarkers & $1: 100$ \\
Desmin & Monoclonal mouse & Novocastra, Leica & $1: 100$ \\
$\alpha$-Smooth Muscle Actin (SMA) & Monoclonal mouse & Novocastra, Leica & $1: 50$ \\
vimentin & Monoclonal mouse & Dako & $1: 150$ \\
Estrogen receptor (ER) & Monoclonal mouse & Novocastra, Leica & $1: 40$ \\
Progesterone receptor (PR) & Monoclonal mouse & Novocastra, Leica & $1: 100$ \\
\hline
\end{tabular}

Table 4. Scoring of immunoreactions panel.

\begin{tabular}{ccccc}
\hline \multirow{2}{*}{ Marker } & \multicolumn{4}{c}{ Localization } \\
\cline { 2 - 5 } Cytokeratin (CK)19 & CCC cells & Muscle cells & Connective tissue cells & Vessels \\
\hline Transforming Growth Factor (TGF)- $\beta 1$ & +++ & - & - & + \\
Carcinoembryonic Antigen (CEA) & +++ & ++ & - & - \\
Desmin & ++ & + & - & - \\
$\alpha$-Smooth Muscle Actin (SMA) & +++ & +++ & - & - \\
vimentin & - & - & +++ & - \\
Estrogen receptor (ER) & ++ & - & - & - \\
Progesterone receptor (PR) & + & - & - & -
\end{tabular}

as not yet well defined [5]. Vang et al. [14] described immunophenotype by using different markers (CK7, CK20, CAM5.2., 34ßE12, CEA, LeuM, vimentin, Bcl2, p53, CA-125, ER, PR,Her2neu). They found CK20 and PR negativity in the tumor. Arai et al. [1] obtained positive reactions using other markers (p53, cyclin A, P-glycoprotein) despite no or low expression of cyclin E, E-cadherin and PR in the tumor. In the case presentation, CK19, which is high molecular weight keratin, was found positive in contrast to what is stated in those documents. Accordingly, CEA was found positively, although the estrogen and progesterone receptors poorly reacted in some CCC cells. As new immunomarkers in this case presentation, it is demonstrated that VGEF, TGF- $\beta, \alpha$ SMA, vimentin and desmin, gave moderate to strong reactions in these cells as well as muscle cells (by aSMA and desmin), connective tissue cells (by vimentin) and vessel endothelial cells (by VGEF). According to the origin of the cells, all reactions were commented as not only epithelial but mesenchymal as well. So, epithelial-mesenchymal transition or any interactions might have occurred as result of myometrial invasiveness of the tumor as for invasive endometrial carcinomas described by Mirantes et al. [11].

In conclusion, this case is thought to be unique on basis of literature because it is rarely encountered in gynecopathology. Thus, cervical clear cell carcinoma has been found highly remarkable because of first presentation in a bitch among the basis of veterinary gynecopathological literature reviews.

\section{MANUFACTURERS}

${ }^{1}$ Fresenius Kabi. Vevey, Switzerland.

${ }^{2}$ Abbott Laboratories Ltd. Sittingbourne, UK.

${ }^{3}$ Leica. Wetzlar, Germany.

Declaration of interest. The authors report no conflicts of interest. The authors alone are responsible for the content and writing of the paper. 


\section{REFERENCES}

1 Arai T., Watanabe J., Kawaguchi M., Kamata, Y., Nishimura Y., Jobo T. \& Kuramoto H. 2006. Clear cell adenocarcinoma of the endometrium is a biologically distinct entity from endometrioid adenocarcinoma. International Journal of Gynecological Cancer. 16(1): 391-395.

2 Cirisano F.D., Robboy S.J., Dodge R.K., Bentley R.C., Krigman H.R., Synan I.S., Soper J.T. \& Clarke-Pearson D.L. 1999. Epidemiologic and surgicopathologic findings of papillary serous and clear cell endometrial cancers when compared to endometrioid carcinoma. Gynecologic oncology. 74(3): 385-394.

3 Creasman W.T., Odicino F., Maisonneuve P., Quinn M.A., Beller U., Benedet J.L., Heintz A.P.M., Ngan H.Y.S. \& Pecorelli S. 2006. Carcinoma of the corpus uteri. International Journal of Gynecology \& Obstetrics. 95: 105-143.

4 Fadare O., Zheng W., Crispens M.A., Jones H.W.I., Khabele D., Gwin K., Liang S.X., Mohammed K., Desouki M.M., Parkash V. \& Hecht J.L. 2013. Morphologic and other clinicopathologic features of endometrial clear cell carcinoma: a comprehensive analysis of 50 rigorously classified cases. American Journal of Cancer Research. 3(1): 70-95.

5 Gadducci A., Cosio S., Spirito N. \& Cionini L. 2010. Clear cell carcinoma of the endometrium: a biological and clinical enigma. Anticancer Research. 30(4): 1327-1334.

6 Hiromura T., Tanaka Y.O., Nishioka T., Satoh M. \& Tomita K. 2009. Clear cell adenocarcinoma of the uterine cervix arising from a background of cervical endometriosis. The British Journal of Radiology. 82(973): e20-e22.

7 Kanbour-Shakir A. \& Tobón H. 1991. Primary clear cell carcinoma of the endometrium: a clinicopathologic study of 20 cases. International Journal of Gynecological Pathology. 10(1): 67-78.

8 Lax S.F., Pizer ES., Ronnett B.M. \& Kurman R.J. 1998. Clear cell carcinoma of the endometrium is characterized by a distinctive profile of p53, Ki-67, estrogen, and progesterone receptor expression. Human Pathology. 29(6): 551-558.

9 Malpica A., Tornos C., Burk T.W. \& Silva E.G. 1995. Low-stage clear-cell carcinoma of the endometrium. The American Journal of Surgical Pathology. 19(7): 769-774.

10 McEntee K. 1990. The Uterus: Atrophic, Metaplastic, and Proliferative Lesions In: Reproductive Pathology of Domestic Mammals. New York: Academic Press, pp.179-219.

11 Mirantes C., Espinosa I., Ferrer I., Dolcet X., Prat J. \& Matias-Guiu X. 2013. Epithelial-to-mesenchymal transition and stem cells in endometrial cancer. Human Pathology. 44(10): 1973-1981.

12 Nikam D.S. \& Katke R.D. 2013. Clear cell carcinoma of the uterine cervix: A case series of five patients. Journal of Case Reports. 3(2): 455-459.

13 Rabban T. 2015. A Contemporary Approach to Pathologic Diagnosis of Endometrial Cancer. <Online access: http:// pdf.thepdfportal.net/PDFFiles/299963.pdf>.[Accessed online in January 2017].

14 Vang R., Whitaker B.P., Farhood A.I., Silva E.G., Ro J.Y. \& Deavers M.T. 2001. Immunohistochemical analysis of clear cell carcinoma of the gynecologic tract. International Journal of Gynecological Pathology. 20(3): 252-259. 